\title{
Study on Movement of Water and Salt through Soil Column and Utilization of Hydrus-1D Program to Simulate Five Scenarios of Crop Production in Salt Affected Paddy Soil
}

\author{
Panom Chaiyasit $^{1}$, Piya Duangpatra ${ }^{1}$, Visoot Verasan $^{2} \&$ Varawoot Vudhivanich $^{3}$ \\ ${ }^{1}$ SLUSE Program, Graduate School, Kasetsart University, Thailand \\ ${ }^{2}$ Department of Soil Science, Faculty of Agriculture, Kasetsart University, Kamphaengsaen Campus, Thailand \\ ${ }^{3}$ Irrigation Technology Research Lab., Department of Irrigation Engineering, Faculty of Engineering, Kasetsart \\ University, Kamphaengsaen Campus, Thailand \\ Correspondence: Panom Chaiyasit, SLUSE Program, Graduate School, Kasetsart University, Bangkok 10900, \\ Thailand. E-mail: panom.chai@gmail.com
}

Received: October 16, 2015

Accepted: October 26, $2015 \quad$ Online Published: December 20, 2015

doi:10.5539/mas.v10n1p139

URL: http://dx.doi.org/10.5539/mas.v10n1p139

\begin{abstract}
An experiment was conducted on the purpose to study movement of water and salt through soil column. Salt-affected paddy soil was assessed for its relevant transport parameters consisting of the hydraulic and the solute transport parameters. The hydraulic parameters included soil hydraulic conductivity $\left(\mathrm{K}_{\mathrm{s}}\right)$ and the van Genuchten's parameters $\left(\theta_{\mathrm{s}}, \theta_{\mathrm{r}}, \alpha\right.$, and $\left.\mathrm{n}\right)$. In this experiment the solute transport parameters was referred to the coefficient of Langmuir's isotherm which consisted of $k_{d}$ and $\eta$. Experience showed that hydraulic parameters were sensitive to changes of soil bulk density $\left(\rho_{b}\right)$. Therefore pedotransfer functions describing the relations between these parameters with $\rho_{\mathrm{b}}$ were established. Straight line functions were found for $\theta_{\mathrm{s}}$ and $\mathrm{n}$, exponential functions were found for $\alpha$ and $\mathrm{K}_{\mathrm{s}}$, and logarithmic function was found for $\theta_{\mathrm{r}}$. Packing the soil in the physical column inevitably caused horizontal differentiation of different $\rho_{\mathrm{b}}$. Bulk density of each layer was estimated by analysis of water flow through soil column at steady-state. Then $\rho_{b}$ of each layer was calculated from the relation $\mathrm{K}_{\mathrm{s}}\left(\rho_{\mathrm{b}}\right)$. After the $\rho_{\mathrm{b}}$ was known the van Genuchten's parameters were calculated from the pedotransfer functions. A physical column of 4 inches diameter and $50 \mathrm{~cm}$ length was constructed. Sodium chloride solution EC $6 \mathrm{dS} / \mathrm{m}$ was fed on soil surface during the process of salinization and the feeding solution was changed to fresh water during the process of desalinization. Breakthrough solution was analyzed for $\mathrm{Na}$ concentration and the breakthrough curves were constructed. The relevant parameters as well as initial and boundary conditions were fed into Hydrus-1D on the purpose to simulate the breakthrough curves. Statistical comparison results using t-test and RMSE suggested that Hydrus-1D could be used successfully to monitor transport of water and salt through soil column.

Five scenarios concerning water and solute transport through soil profile under rice and mung bean cropping were simulated using Hydrus-1D. Simulation results suggested that continuous flooding was the most efficient way to leach soluble salts down to ground water. Wet/dry irrigation scheme for rice production could drain salts only when rice crop was in the first period of growth where crop water uptake was small. During later stages of growth concentration profile of $\mathrm{Na}$ remained almost unchange indicating negligible downward movement of salts. Leaving the soil to dry naturally during the dry season caused upward accumulation of salt to the degree smaller than cultivating mung bean since water content and hence the diffusion coefficient of the soil were higher and more favorable for upward salt diffusion than in the former case. Inserting the capillary rise hindering soil layer underneath mung bean root zone was found to retard upward diffusion of salt to the degree comparable to leaving the soil to dry naturally.
\end{abstract}

Keywords: transport parameter, pedotransfer function, movement of water and salt through soil column, Hydrus-1D simulation, crop production, salt affected soil

\section{Introduction}

Soil salinity is an important problem for plant production in the North-eastern part of Thailand especially in the district of Tung Sumrit in Nakorn Ratchasima and Buriram provinces. Salt-problem soil originates from deposit 
of rock salt bedding that creates saline ground water. In an event that ground water rises close to ground level salts may move with capillary water and deposit in surface layer of soil during dry season and thereby causes salt-affected soil unsuitable for crop production (Dutthuyawat, 2011).

Saline soil is defined as the soil having electrical conductivity (EC) more than $4 \mathrm{dS} / \mathrm{m}$. The detrimental effect of soil salinity is caused by reduction of osmotic and total potentials of soil water and consequently reduces root water absorption and causes crop water stress. Alternatively, excessive salt accumulation can create salt toxicity and crop death. There are two practical ways to alleviate such the problem; using salt-tolerated crop cultivars or management practices that reduce salt content in the vicinity of crop root zone. Leaching of salt from surface layer by flooding followed by cutting capillary rise of saline ground water by some means as well as retardation of surface evaporation by mulching are among those practices (U. S. Salinity Laboratory Staff, 1954).

Normally, salt-affected soils at a certain degree can be used for paddy rice production during rainy season since soil salinity is reduced by water dilution accompanied by cultivating rice by transplanting method. During dry season salts again move back to accumulate in surface layer with evaporating water and hinder crop growth in dry season. Growing mung bean as a second crop following rice might reduce ascent of salts by supplementary irrigation.

Flow of water through soil in transient-state flow condition can be described by Richard's equation.

$$
\frac{\partial \theta}{\partial t}=\frac{\partial}{\partial z}\left(D_{w}(\theta) \frac{\partial \theta}{\partial z}\right)+\frac{\partial}{\partial z}(K(\theta))
$$

Where $\theta, z$, and $t$ are water content, depth, and time variables, respectively. $K(\theta)$ is soil hydraulic conductivity and $D_{w}(\theta)$ is soil water diffusivity expressed as a function of water content and can be calculated from equation (2)

$$
D_{w}(\theta)=K(\theta) \frac{d h}{d \theta}
$$

Where $\mathrm{dh} / \mathrm{d} \theta$ is the slope of the soil water retention curve.

Transport of solute through soil can occur only when solutes dissolve in water and/or volatilize in soil air. In the case of reactive (adsorbing) solute, the solute transport equation may be described as a convection-dispersion equation (CDE) as follows.

$$
\frac{\partial}{\partial t}\left(\rho_{b} C_{a}+\theta C_{l}\right)=\frac{\partial}{\partial z}\left(D_{e} \frac{\partial C_{l}}{\partial z}\right)-\frac{\partial}{\partial z}\left(J_{w} C_{l}\right)-r_{S}
$$

Where $\rho_{b}$ is soil bulk density, $C_{a}$ is adsorb concentration of solute on soil particle, $\theta$ is soil volumetric water content, $C_{1}$ is solute concentration in soil solution, $D_{e}$ is effective diffusion-dispersion coefficient, and $r_{s}$ is the reaction rate per volume (Jury et al., 1991).

Hydrus-1D updated version 4.16.0110 was developed by Simunek and his colleges in 2014. Hydrus-1D is a public domain Windows-based modeling environment for analysis of water flow and solute transport in variably saturated porous media. The software package includes the one-dimensional finite element model HYDRUS for simulating the movement of water, heat, and multiple solutes in variably saturated media. The model is supported by an interactive graphics-based interface for data-preprocessing, discretization of the soil profile, and graphic presentation of the results (Simunek et al., 2013).

Hydrus-1D was successfully used to simulate movement and balance of water (Yong et al., 2014) and nitrogen in rice paddies (Yong et al., 2015). However, simulation by Hydrus-1D favored the wet/dry irrigation pattern for rice crop if transpiration was considered since the program would assign zero uptake if the soil was water saturated. Few articles were found concerning Hydrus-1D simulation on water and salt movement through root zone of other crops.

The aim of this study was to evaluate the relevant parameters necessary for solving transports of water and salt through profile of salt affected soil packed in soil columns. Validation of the acquired parameters was made by comparing the breakthrough curves between observed data and Hydrus-1D outputs during salinize- and desalinization of soil column. Hydrus-1D computer software was used to simulate movement of water and salt through soil under wet and dry season, cropping with rice and mung bean and to monitor profile information of water and salt as well as fluxes through the upper and lower boundaries of soil columns. 


\section{Method}

\subsection{Physical Characteristics of the Test Soil}

Saraburi soil series (Ustic Endoaquerts) was chosen as a test soil since it has soil texture analysis results similar to the salt affected Phimai soil series (Chromic Ustic Endoaquerts) of the study area. The test soil was collected from a paddy field of Kasetsart University, Kampheangsaen campus, Thailand. Results of soil textural analysis and some of its physical properties were given in figure (1).

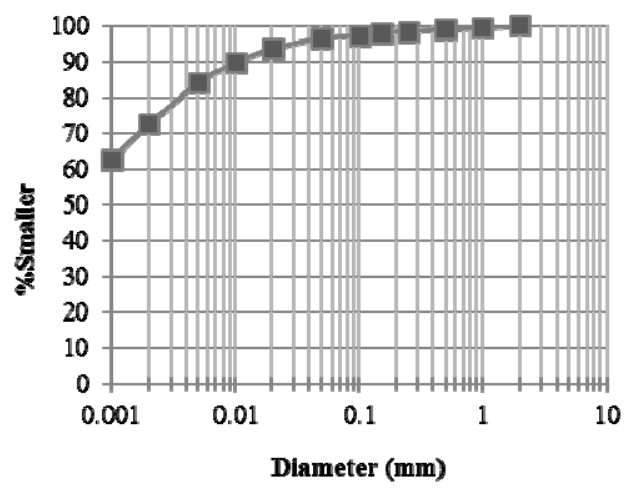

(a)

\begin{tabular}{|l|r|}
\hline$\%$ Sand & 6.32 \\
\hline$\%$ Silt & 21.21 \\
\hline$\%$ Clay & 72.47 \\
\hline Texture & Clay \\
\hline $\mathrm{\rho b}(\mathrm{g} / \mathrm{cm} 3)$ & 1.267 \\
\hline $\mathrm{Ks}(\mathrm{m} /$ day $)$ & 0.00825 \\
\hline
\end{tabular}

(b)

Figure 1. Some physical properties of the test soil, (a) particle-size distribution, and (b) soil texture, bulk density $\left(\rho_{\mathrm{b}}\right)$, and saturated hydraulic conductivity $\left(\mathrm{K}_{\mathrm{s}}\right)$

\subsection{Evaluation of Transport Parameters}

\subsubsection{Hydraulic Parameters}

The hydraulic parameters consist of the van Genuchten's parameters and saturated hydraulic conductivity $\left(\mathrm{K}_{\mathrm{s}}\right)$. Soil water retention curve was constructed by using pressure plate extractors and the scattered points were fitted to van Genuchten's model (equation (4)) using Matlab software.

$$
\theta(h)=\theta_{r}+\frac{\theta_{S}-\theta_{r}}{\left(1+(\alpha|h|)^{n}\right)^{\left(1-\frac{1}{n}\right)}}
$$

In this case the Van Genuchten's parameters, $\theta_{\mathrm{s}}$ and $\theta_{\mathrm{r}}$ were saturated- and residual water content, $\alpha$ and $\mathrm{n}$ were constants. Saturated hydraulic conductivity was evaluated by using the falling head permeameter and the method proposed by Verasan et al. (2006).

\subsubsection{Solute Transport Parameters}

The solute transport parameter included soil bulk density $\left(\rho_{\mathrm{b}}\right)$ and the adsorption isotherm parameters. Soil bulk density was determined by core method. Soil sample passing through $2.0 \mathrm{~mm}$ sieve was packed gently to fill up a stainless steel soil core and then weighed for dry soil mass. Bulk density was obtained by dividing dry soil mass with core volume.

The adsorption isotherm (i.e. the relationship between adsorbed concentration and liquid concentration at equilibrium) of sodium ion was constructed and the data points were fitted to Langmuir isotherm (equation (5)) using Matlab.

$$
C_{a}=\frac{k_{d} C_{l}}{1+\eta C_{l}}
$$

Where $C_{a}$ was the adsorbed concentration and $C_{1}$ was the concentration of $\mathrm{Na}$ in equilibrium solution. In this case the adsorption isotherm parameters were $K_{d}$ and $\eta$.

According to the fact that values of soil hydraulic parameter may change with pore-size distribution of the soil which in turn governs by particle packing designated by soil bulk density. The study on relationship between each hydraulic parameter with bulk density was made by packing the soil to a feasible range of bulk density. The individual compacted soil samples were then used to construct water retention curves and the hydraulic 
parameters at each density were determined. Mathematical functions describing the relationship between each parameter as well as Ks and bulk density was evaluated using Matlab software. These functions were used to estimate the value of each parameter according to actual bulk density of the compacted soil sample.

\subsection{Salinization and Desalinization of the Physical Model}

\subsubsection{Horizon Differentiation of Soil in the Physical Column}

The soil column in this experiment consisted of 5 individual soil cores each $10 \mathrm{~cm}$ in length assembled by o-ring sealed collars. Soil core was made from 4-inch PVC pipe cut to the desired length. Bottom piece of the column was made from PVC plug of the same size containing a plastic screen to retain soil sample. Extra core was attached to the top of soil column to retain irrigation water. A hole $23.5 \mathrm{~mm}$ diameter was drilled through the side at the middle of the $1^{\text {st }}, 3^{\text {rd }}$, and $5^{\text {th }}$ cores to access a tensiometer. Four holes of the same size were drilled at the middle of the $2^{\text {nd }}$ and $4^{\text {th }}$ cores as passages for soil sample collection. In packing soil column, a correct amount of soil was weighed into soil core to make $1.267 \mathrm{~g} / \mathrm{cm}^{3}$ of bulk density. A sealed collar was pushed in place and then the next soil core. The process was repeated until the $5^{\text {th }}$ core was filled and then the extra core to retain irrigation water was put in place. As for the process of soil packing being mentioned, we found that the soil particles contained in soil column rearranged themselves into layers of different bulk density. We differentiated soil layers by analysis of water flow through soil column at steady-state condition as followed: Since tensiometers were inserted at depths 5,25 , and $45 \mathrm{~cm}$ therefore 4 soil layers, $0-5,5-25,25-45$, and 45-50 depth intervals could be separated according to flow analysis. During steady-state saturated flow where pressure heads at soil surface and at the bottom were set at constant values and the pressure head along flow path was monitored by soil manometer, hydraulic head gradient across each layer could be calculated. As a consequence of steady-state flow, fluxes of water through each layer and the total flux measured at the bottom of soil column must be equal. By this concept saturated hydraulic conductivity $\left(\mathrm{K}_{\mathrm{s}}\right)$ of each layer could be calculated by the ratio between water flux and hydraulic head gradient. Since the function between $K_{s}$ and $\rho_{b}$ was known, bulk density of each layer could be determined. Consequently, the hydraulic parameters of each layer could be calculated from the value of bulk density by the pedotransfer functions formerly constructed.

\subsubsection{Column Test}

\section{1) Salinization}

The test soil was packed into $50 \mathrm{~cm}$ physical column by the method stated earlier. The soil was saturated by immersing the column in water to the level of soil surface until water film was noticed on it. After the column was transferred onto its base, a set of graduated constant head reservoir containing EC $6 \mathrm{dS} / \mathrm{m} \mathrm{NaCl}$ solution was set in place. The unit was assigned to generate a constant level of water ponding at $5 \mathrm{~cm}$. A drain plug was assembled and drainage water was collected by daily routine. Concentration of $\mathrm{Na}$ ion in the leachate was determined by atomic absorption spectrophotometer. Then the breakthrough curve was constructed as the relation between the liquid concentration of $\mathrm{Na}$ ion and time. By the way, the initial and boundary conditions of water and salt as well as the relevant parameters were fed to Hydrus-1D computer program to simulate movement of water and salt. The output on concentration of $\mathrm{Na}$ at the bottom of soil surface was plotted against time in the same graph to compare the simulation result to the observed value.

\section{2) Desalinization}

After the salinization process was finished, solution in the constant head reservoir was changed to fresh water and being fed into soil column under the same condition as in salinization. The leaching solution was analyzed for $\mathrm{Na}$ and being plotted with time as before to obtain the breakthrough curve. Result from simulation by the Hydrus-1D program was added into the graph and comparison was made between the predicted and the observed values.

\subsubsection{Statistical Test}

The difference between means of predicted and observed values in salinization and desalinization scenarios was detected for statistical significance by the method of t-test (Rowell, 1994). And the point-to-point comparison was performed using the root mean square error (RMSE) as suggested by Van Donk et al. (2004) as in equation (6).

$$
R M S E=\sqrt{\frac{\sum_{i=1}^{n}\left(y_{i}-\hat{y}_{i}\right)^{2}}{n}}
$$

Where $\mathrm{n}$ is the number of observation, $y_{i}$ and $\hat{y}_{i}$ are the observed and the predicted values, respectively 
Five events of interest on water and solute transport through soil under bare and cropping conditions were designed for Hydrus-1D simulation. The simulation consisted of two seasons, rainy season for rice production and dry season for mung bean production. Scenario 1 simulated the steady state saturated downward movement from stagnant fresh water $5 \mathrm{~cm}$ depth on soil surface through soil having initial EC of $6 \mathrm{dS} / \mathrm{m}$. The seepage face scheme and the zero concentration gradient were assigned to the lower boundary condition at $47 \mathrm{~cm}$ depth for water and salt, respectively. Scenario 2 simulated transient state movement of water and salt in wet/dry rice cropping under atmospheric boundary condition where average rainfall of $10 \mathrm{~mm} /$ day and evapotranspiration during the four months as a second order polynomial function with time during the rainy season were given as the input for the upper boundary. The constant pressure head and the constant concentration were assigned as the lower boundary condition for water and salt, respectively. Scenario 3 simulated movement of water and salt in dry season. Atmospheric boundary condition with no precipitation was assigned to soil surface. Evaporation from soil surface was appointed as a power function of the form: $y=a x^{-b}$ where saturated soil water content was assumed at the beginning of evaporation. The constant pressure head and the constant concentration were assigned as the lower boundary condition for water and salt, respectively, as in scenario 2. Scenario 4 simulated the movement under mung bean cropping in dry season following rice production. Atmospheric boundary condition and zero flux were assigned for water and salt movement through the top surface. Weekly irrigation accounting for $8 \mathrm{~mm} /$ day water use was given throughout the simulation period and surface evaporation was assigned as a straight line function and transpiration as a second order polynomial function with time during the dry season. The lower boundary conditions for water and salt were assigned as in scenario 2 . The upper and lower boundary conditions as well as other obligations for scenario 5 were assigned identical to scenario 4 accept that a $10 \mathrm{~cm}$ layer of loosely packed soil was inserted at $10-20 \mathrm{~cm}$ depth interval. The soil in this layer possessed a special pore-size distribution that favor downward movement and imped upward movement of water promoting leaching and inhibiting capillary rise of salt. The initial conditions of soil simulated the events under the rainy season were set at saturated water content and $\mathrm{EC}$ of $6 \mathrm{dS} / \mathrm{m}$ while that of the soil under the dry season were at saturated water content and EC of $2 \mathrm{dS} / \mathrm{m}$.

\section{Results and Discussion}

\subsection{Transport Parameters}

\subsubsection{Hydraulic Parameters}

Water retention curve of the test soil was illustrated in figure (2a). Van Genuchten's equation was imposed on the data points and the values of the relevant parameters acquired by Matlab software were given in figure $(2 \mathrm{~b})$.

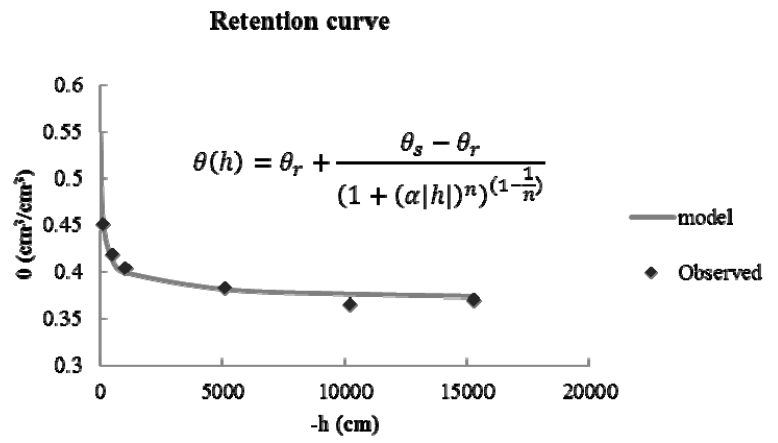

(a)

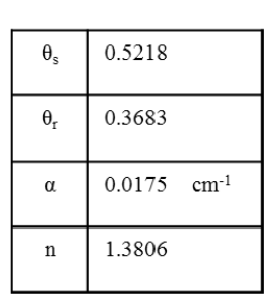

(b)

Figure 2. Soil water retention curve with Van Genuchten's equation (a) and Van Genuchten's parameters acquired by Matlab software (b)

The saturated hydraulic conductivity $\left(\mathrm{K}_{\mathrm{s}}\right)$ was measured by falling-head method and was found to be 0.00825 $\mathrm{m} /$ day. The values of van Genuchten's parameters and $\mathrm{K}_{\mathrm{s}}$ were estimated at bulk density of $1.267 \mathrm{~g} / \mathrm{cm}^{3}$.

\subsubsection{Solute Transport Parameter}

The adsorption isotherm of $\mathrm{Na}$ ion obtained from column test by analyzing the adsorbed $\mathrm{Na}$ and the corresponding free $\mathrm{Na}$ in soil solution during salinization and desalinization activities was given in figure (3a). The data points were fitted to Langmuir's isotherm and the Langmuir's parameters including bulk density were presented in figure (3b). 


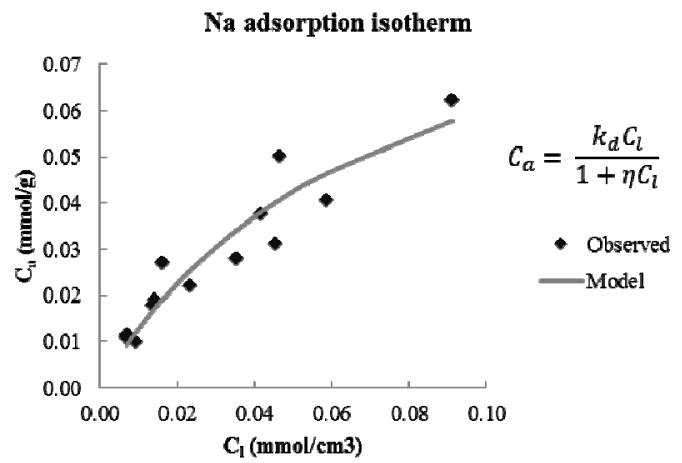

(a)

\begin{tabular}{|c|l|}
\hline$k_{d}$ & $1.442\left(\mathrm{~cm}^{3} / \mathrm{g}\right)$ \\
\hline$\eta$ & $13.996\left(\mathrm{~cm}^{3} / \mathrm{mmol}\right)$ \\
\hline$\rho_{b}$ & $1.267\left(\mathrm{~g} / \mathrm{cm}^{3}\right)$ \\
\hline
\end{tabular}

(b)

Figure 3. Solute transport parameters: (a) Langmuir isotherm and (b) Langmuir parameters

\subsubsection{Relationship between Transport Parameters and Soil Bulk Density}

In response to the difficulty in packing the soil to the same bulk density throughout the physical column, the relationship between the hydraulic parameters and bulk density were established. The results were given in figure (4).
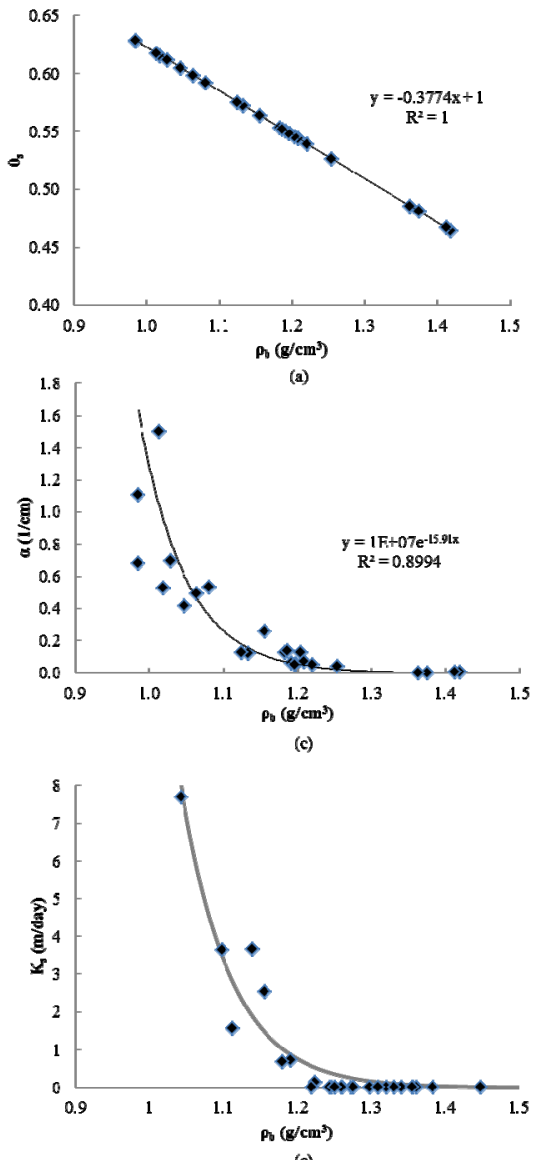

Figure 4. Relationships between hydraulic parameters and bulk density of the test soil: (a) saturated water content $\left(\theta_{\mathrm{s}}\right)$, (b) residual water content $\left(\theta_{\mathrm{r}}\right),(\mathrm{c})$ alpha parameter $(\alpha),(\mathrm{d}) \mathrm{n}$ parameter $(\mathrm{n})$, and (e) saturated hydraulic conductivity $\left(\mathrm{K}_{\mathrm{s}}\right)$ 
The relationships between $\theta_{\mathrm{s}}$ and $\mathrm{n}$ to bulk density assumed straight line functions while that of $\alpha$ and $\mathrm{K}_{\mathrm{s}}$ were exponential and for $\theta_{\mathrm{r}}$ it was logarithmic. The established functions were shown in table (1).

Table 1. Mathematical functions relating hydraulic parameters of the test soil to its bulk density

\begin{tabular}{ccccc}
\hline Saturated water content & Residual water content & Alpha parameter & N parameter & Saturated hydraulic conductivity \\
\hline$\theta_{s}=-0.377 \rho_{b}+1$ & $\theta_{r}=0.338 \ln \left(\rho_{b}\right)+0.276$ & $\alpha=10^{7} e^{-15.91 \rho_{b}}$ & $n=0.487 \rho_{b}+0.763$ & $K_{s}=4.74 \times 10^{7} e^{-14.97 \rho_{b}}$ \\
\hline
\end{tabular}

\subsection{Salinization and Desalinization of the Physical Model}

\subsubsection{Soil Horizon Differentiation in the Physical Column}

During the process of salinization and desalinization where steady-state saturated flow occurred, analysis of flow equation could yield 4 horizon differentiations according to the position of the tensiometers imbedded at 5,25 and $45 \mathrm{~cm}$ where pressure heads $h_{1}, h_{2}$, and $h_{3}$ were monitored. In this case $h_{0}$ at the top surface was the depth of ponding and $\mathrm{h}_{4}$ at the bottom surface was approximately zero. Schematic diagram showing horizon differentiation was given in figure (5).

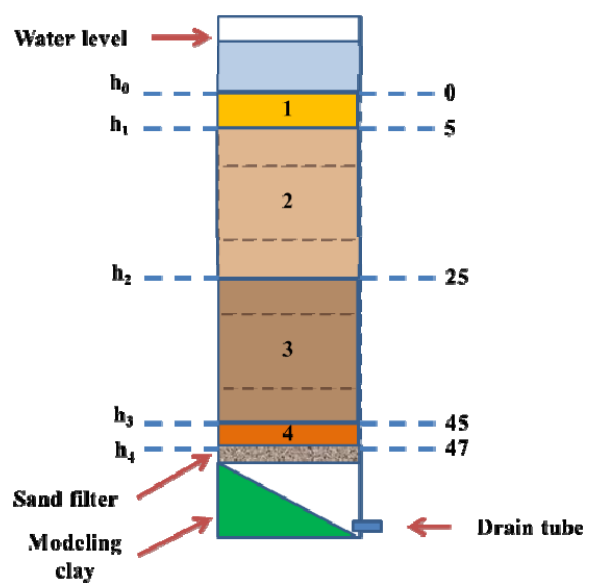

Figure 5. Soil horizon could be differentiated into 4 layers according to the positions of the tensiometers and analysis of water flow at steady-state condition

The results of horizon differentiation during salinization and desalinization were given in table (2) and (3). By analysis of water flow mentioned earlier the values of Ks were obtained for each layer, and then the values of bulk density were calculated from the relation between the two. Finally, the hydraulic parameters were predicted from the relations given in table (1).

Table 2. Soil horizon differentiation in the physical column during salinization event

\begin{tabular}{ccccccc}
\hline Layer & $\mathrm{K}_{\mathrm{s}}(\mathrm{cm} /$ day $)$ & $\rho_{\mathrm{b}}(\mathrm{g} / \mathrm{cm} 3)$ & $\theta_{\mathrm{r}}$ & $\theta_{\mathrm{s}}$ & $\alpha(1 / \mathrm{cm})$ & $\mathrm{n}$ \\
\hline 1 & 33.538 & 0.946 & 0.265 & 0.643 & 2.894 & 1.224 \\
2 & 17.489 & 0.990 & 0.278 & 0.626 & 1.448 & 1.246 \\
3 & 1.856 & 1.140 & 0.320 & 0.570 & 0.133 & 1.319 \\
4 & 0.603 & 1.215 & 0.341 & 0.542 & 0.040 & 1.355 \\
\hline
\end{tabular}

Table 3. Soil horizon differentiation in the physical column during desalinization event

\begin{tabular}{ccccccc}
\hline Layer & $\mathrm{K}_{\mathrm{s}}(\mathrm{cm} /$ day $)$ & $\rho_{\mathrm{b}}(\mathrm{g} / \mathrm{cm} 3)$ & $\theta_{\mathrm{r}}$ & $\theta_{\mathrm{s}}$ & $\alpha(1 / \mathrm{cm})$ & $\mathrm{n}$ \\
\hline 1 & 7.014 & 1.051 & 0.295 & 0.603 & 0.548 & 1.275 \\
2 & 5.498 & 1.067 & 0.299 & 0.597 & 0.423 & 1.283 \\
3 & 0.341 & 1.253 & 0.351 & 0.527 & 0.022 & 1.374 \\
4 & 0.290 & 1.264 & 0.354 & 0.523 & 0.019 & 1.379 \\
\hline
\end{tabular}


As illustrated in the tables, soil bulk densities were seen to increase and $\mathrm{K}_{\mathrm{s}}$ to decrease with depth according to action of soil packing. The value of $\rho_{\mathrm{b}}$ during desalinization suggested slaking of soil crumbs and increasing in soil compaction in response to dilution of salt solution. As a consequence, the values of $\mathrm{K}_{\mathrm{s}}$ were observed to decrease approximately 4 folds. Naturally, soil compaction would result decrease in fraction of large pores and increase of small pores. By this means, $\theta_{\mathrm{s}}$ was observed to decrease and $\theta_{\mathrm{r}}$ to increase during the process of desalinization. The parameter $\alpha$ was found to decrease and parameter $n$ to increase slightly during desalinization.

\subsubsection{Salinization Result}

As the values of relevant parameter in table (2) and figure (3b) were fed into Hydrus-1D and the output on Na concentration at the bottom of soil column were observed with time, the result was shown as a breakthrough curve in figure (6). In this figure the data points were the observed values obtained by periodic measuring the efflux solutions until the equilibrium was reached. It could be seen that the simulation result was remarkably closed to the observed result.

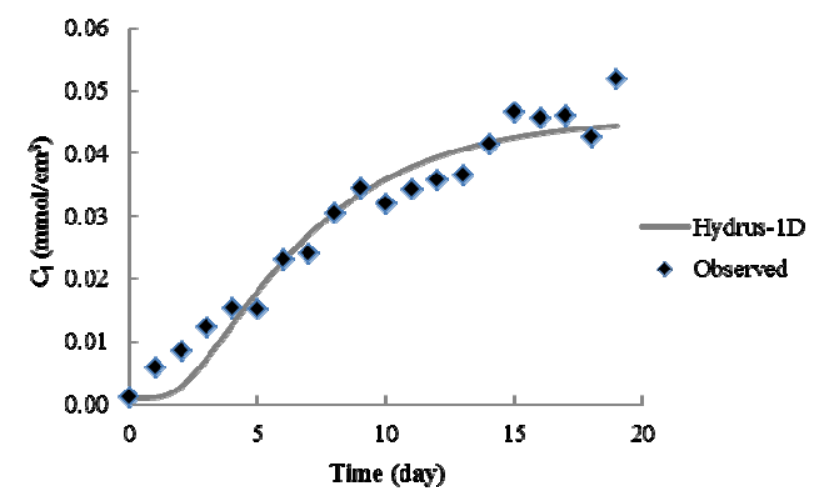

Figure 6. Variation of Na concentration in efflux solution with time during salinization (data points) as compared to simulation result from Hydrus-1D (solid line)

Table (4) demonstrated the result of statistical comparison between the observed and predicted values of Na concentration in the efflux solution. It was noticed that mean value of concentration was not different between the two. The RMSE was $0.004 \mathrm{mmol} / \mathrm{cm}^{3}$ accounting for about $10 \%$ of maximum value of $\mathrm{Na}$ concentration.

Table 4. Statistical comparison between observed and predicted values of breakthrough Na with Hydrus-1D during salinization

\begin{tabular}{ccccc}
\hline RMSE $\left(\mathrm{mmol} / \mathrm{cm}^{3}\right)$ & $\mathrm{t}$-cal & $\mathrm{t}$-table & $\mathrm{t}$-table $/ 2$ & sig. \\
\hline 0.004 & 0.114 & 2.024 & 1.012 & $\mathrm{~ns}$ \\
\hline
\end{tabular}

\subsubsection{Desalinization Result}

Results on desalinization of soil in the physical column expressed in solid line as shown in figure (7) were the consequence after the input parameters in table (3) and figure (3b) were fed into Hydrus-1D. The experiment was not made until equilibrium due to time limit. However, the simulation results were fairly closed to the observed results (the data points). 


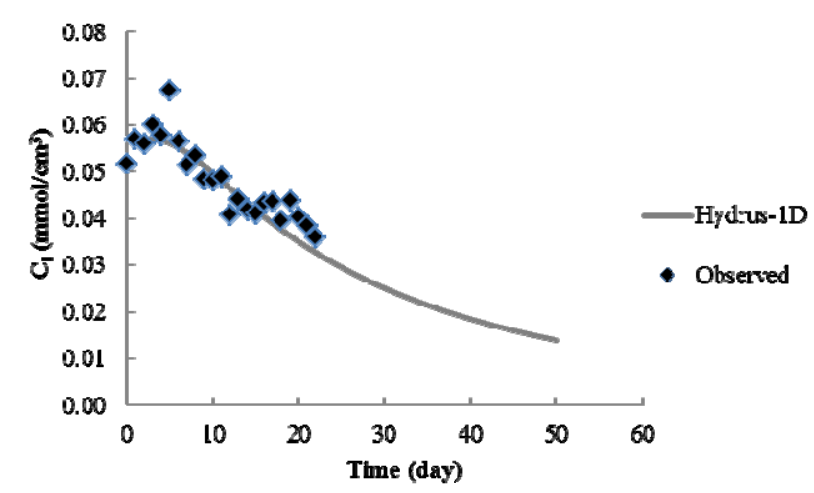

Figure 7. Variation of Na concentration in efflux solution with time during desalinization (data points) as compared to simulation result from Hydrus-1D (solid line)

Statistical comparison given in table (5) revealed the same result as in salinization process. The study on transport of $\mathrm{Na}$ ion through soil column under the process of salinization and desalinization suggested that Hydrus-1D computer program could be used successfully to describe the movement of water and salt.

Table 5. Statistical comparison between observed and predicted value of breakthrough Na with Hydrus-1D during desalinization

\begin{tabular}{ccccc}
\hline RMSE $(\mathrm{mmol} / \mathrm{cm} 3)$ & $\mathrm{t}$-cal & $\mathrm{t}$-table & $\mathrm{t}$-table/2 & sig. \\
\hline 0.004 & 0.471 & 2.016 & 1.008 & $\mathrm{~ns}$ \\
\hline
\end{tabular}

\subsection{Five Crop Production Scenarios Simulated by Hydrus-1D}

\subsubsection{Salt Leaching}

The profiles of pressure head illustrated chronologically throughout the simulation period in figure (8a) were found to oscillate in narrow range between -1 to $5 \mathrm{~cm}$ of water. The pressure head gradients $(\mathrm{dh} / \mathrm{dz})$ were largely positive and the gravitational head gradient $(\mathrm{dz} / \mathrm{dz})$ in this case was a constant equal to +1 . The hydraulic head gradient $(\mathrm{dH} / \mathrm{dz})$ fluctuated along the flow path in response to difference of saturated hydraulic conductivity $\left(\mathrm{K}_{\mathrm{s}}\right)$ in order that water flux was equal throughout the flow region to designate steady-state downward flow. Figure (8b) showed cumulative water flux at top and bottom soil surfaces. Water fluxes at both surfaces were observed to be equal and the graphs were straight line having constant flux density ensuring the steady-state flow condition. The downward movement of fresh water induced movement of salt as might be observed in figure (8c). The concentration of $\mathrm{Na}$ ion in soil solution was lowered from $0.029 \mathrm{mmol} / \mathrm{cm}^{3}$ at the beginning to 0.012 $\mathrm{mmol} / \mathrm{cm}^{3}$ at the end of simulation period. Salt draining rate was fastest at the beginning and being decreased with time as might be observed in figure (8d). In this case, cumulative solute flux at the bottom surface was negative to indicate downward flow direction. The salt balance sheet given in table (6) indicated an overall $\mathrm{Na}$ efflux of $105.17 \mathrm{mmol}$ out of soil column at the end of 100 days of simulation period resulted net Na content of $92.82 \mathrm{mmol}$ containing in soil as adsorbed and free $\mathrm{Na}$. 

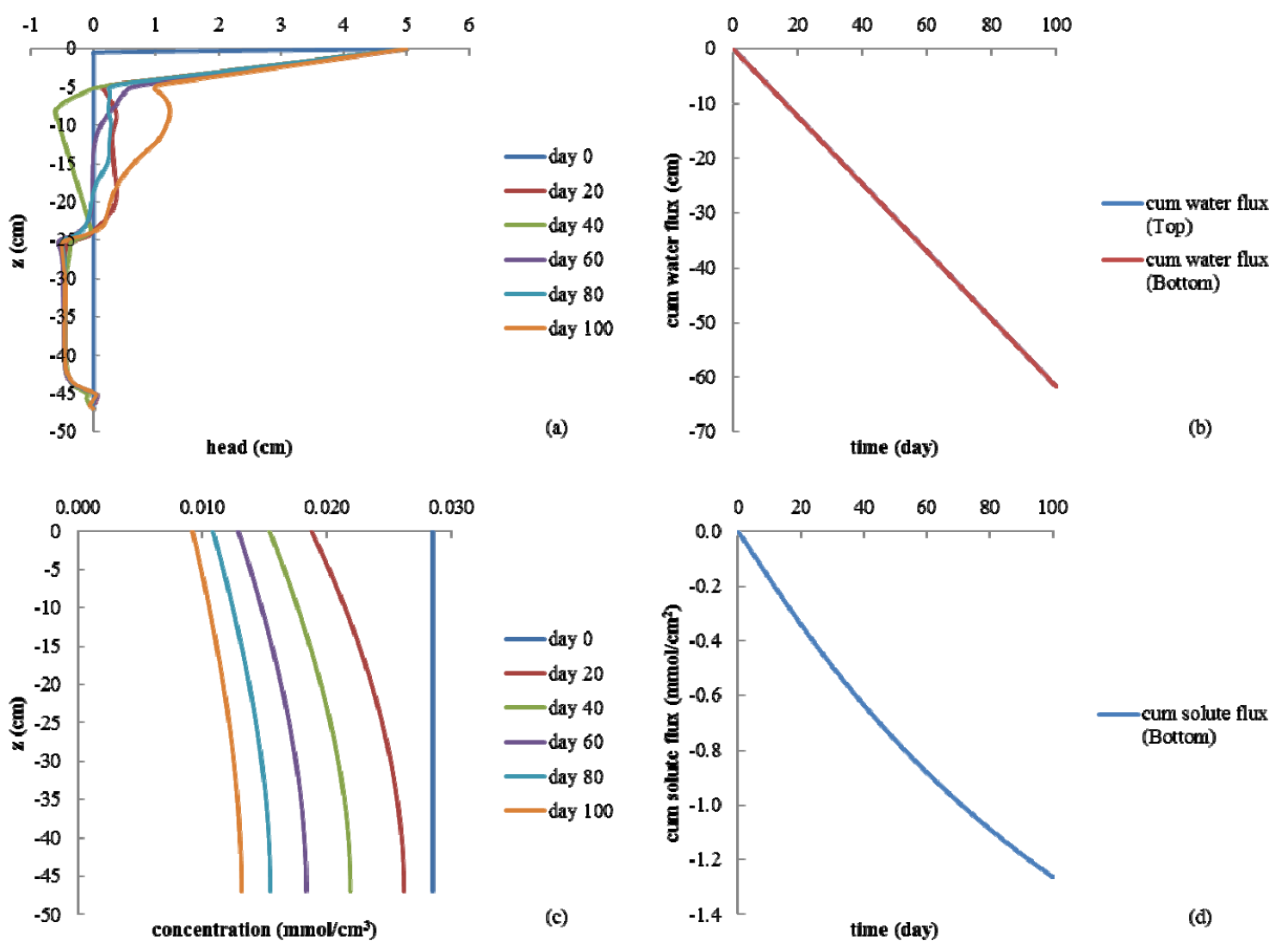

Figure 8. Simulation outputs from Hydrus-1D for salt leaching scenario: (a) pressure head profile, (b) cumulative water fluxes, (c) Na concentration profile, and (d) cumulative bottom solute flux

\subsubsection{Wet/Dry Irrigation Scheme for Rice Cropping}

The other wet season simulation was the wet/dry irrigation scheme for rice cropping scenario. This irrigation scheme was assigned to avoid the constraint of plant water uptake calculation by Hydrus-1D that water uptake will be appointed the value of zero whenever the soil is saturated. Pressure head profiles shown in figure (9a) were the average values before and after each irrigation throughout the period. Pressure head profile 1 day after irrigation suggested that the gravity flow of irrigation water might take place. Later in the irrigation cycle successive percolation and root water uptake brought about profile desiccation and reduction of pressure head that slowed down further downward movement of water. Cumulative water fluxes through the top and bottom boundaries of the soil were given in figure (9b). Again, positive and negative values merely indicated upward and downward movement, respectively. Wavy pattern was observed for each curve in response to cycle of irrigation. The cumulative flux at soil surface was the result of infiltration of irrigation water minus evaporation. Cumulative water flux at the bottom surface was the difference between water flux at the top surface and the cumulative water uptake of rice root provided that soil water content remained constant. Net downward flux at the bottom surface suggested that salt was continually leached out of the soil. Concentration profiles of Na in soil solution were shown in figure $(9 \mathrm{c})$. Larger decrease in concentration was detected for the $2^{\text {nd }}$ and $6^{\text {th }}$ irrigation suggesting rapid drainage of salt as might be seen in figure (9d). Rate of salt leaching late in the simulation period drastically decreased according to desiccation of the soil as a consequence of large root water uptake of mature rice crop. Total efflux of $\mathrm{Na}$ from soil column was $40.68 \mathrm{mmol}$ remarkable smaller than salt leaching scenario because of smaller value of water drainage (table 6) resulting larger net Na retained in the soil (154.71 $\mathrm{mmol}$ ) at the end of the simulation. 

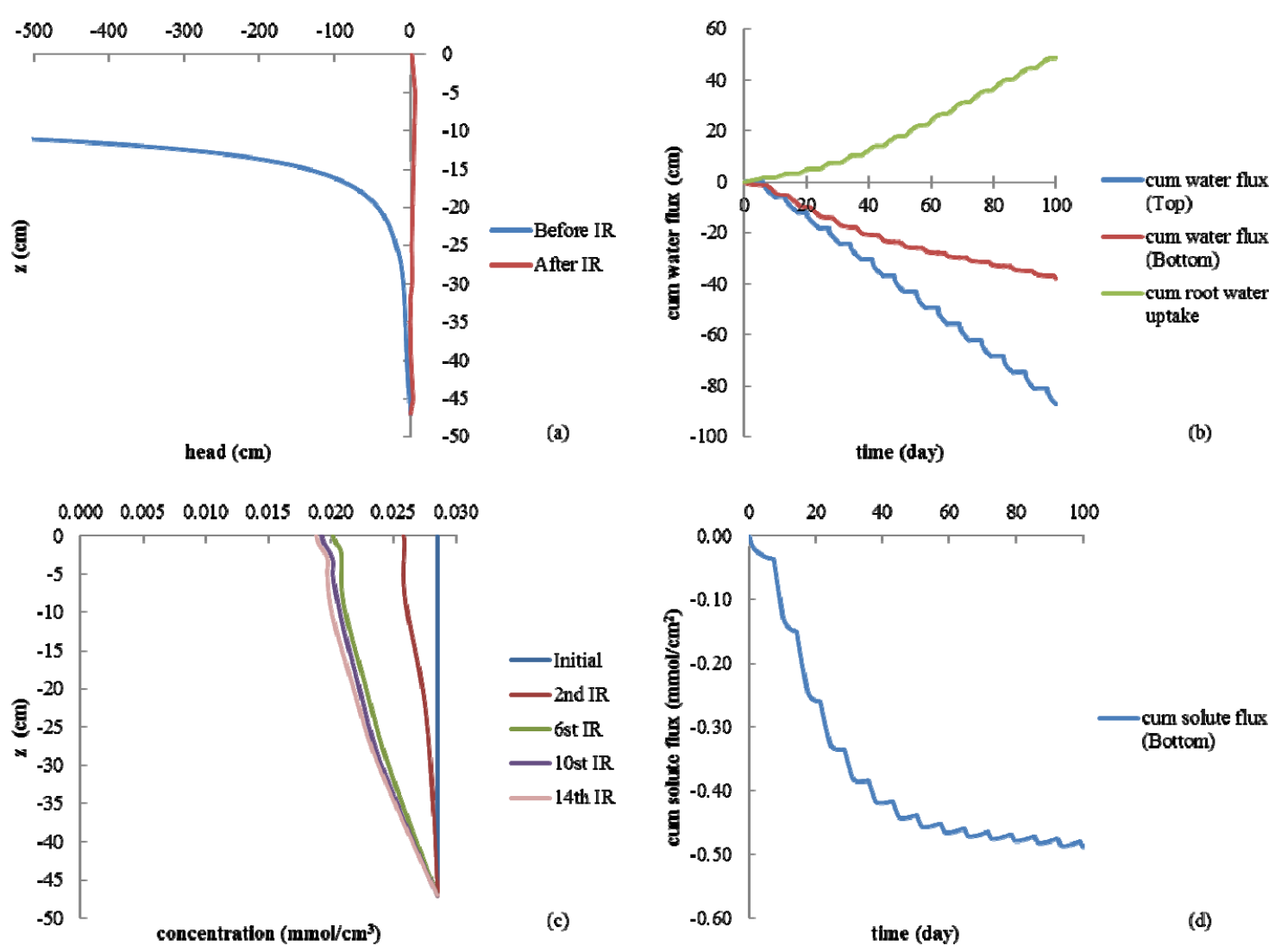

Figure 9. Simulation outputs from Hydrus-1D for rice cropping scensario: (a) pressure head profile, (b) cumulative water fluxes and plant water uptake, (c) Na concentration profile, and (d) cumulative bottom solute flux

\subsubsection{Dry Season Accumulation of Salt}

This scenario simulated capillary rise of water and salt from water table located at $50 \mathrm{~cm}$ depth where ground water was salty $(\mathrm{EC} 6 \mathrm{dS} / \mathrm{m})$. The initial salinity of the soil was set at EC $2 \mathrm{dS} / \mathrm{m}$ uniformly throughout the column. Initial soil water content was set at saturation and surface evaporation rate was assigned as a power function of the form $y=a x^{-b}$. The simulation result on pressure head profiles was shown in figure (10a). Pressure head gradient $(\mathrm{dh} / \mathrm{dz})$ was negative throughout soil column having small negative value around $-0.6 \mathrm{~cm} / \mathrm{cm}$ between $\mathrm{z}=-47 \mathrm{~cm}$ to $\mathrm{z}=-5 \mathrm{~cm}$. Sharp bend of the curve was observed at $\mathrm{z}=-5 \mathrm{~cm}$ where negative pressure head gradient was extremely large. Such the conditions resulted downward movement of water in soil layer -47 to $-5 \mathrm{~cm}$ contributing to downward flux at the bottom surface, and on the other hand, the upward movement of water in the layer -5 to $0 \mathrm{~cm}$ contributing to evaporation at the top surface. Cumulative water flux at both surfaces was illustrated in figure (10b). Very small amount of evaporated water was observed due to extremely dry insulation surface layer of very low hydraulic conductivity. The amount of $2.5 \mathrm{~cm}$ total water drainage out of the bottom surface was observed. Draining rate was faster during the first 25 days of simulation and gradually approached zero at 100 days. Concentration profiles of $\mathrm{Na}$ given in figure (10c) demonstrated upward movement of salt by diffusion process opposing the movement of drainage water. Rate of $\mathrm{Na}$ diffusion was quite rapid during the first 20 days as might be seen in figure (10d) where salt moved up to the depth of $-20 \mathrm{~cm}$. Diffusion rate was seen to decrease with time to the end of simulation period where salt moved only about $10 \mathrm{~cm}$ further to the depth of $-10 \mathrm{~cm}$. Accumulation of salt in the top $10 \mathrm{~cm}$ of soil surface was sparse because of small amount of capillary water. Balance sheet of $\mathrm{Na}$ shown in table (6) indicated an upward movement of $63.98 \mathrm{mmol}$ contributing net $\mathrm{Na}$ content of $109.02 \mathrm{mmol}$, more than twice of the original value. The concentration profile suggested that the influx $\mathrm{Na}$ ion accumulated in the lower -47 to $-20 \mathrm{~cm}$ depth. 

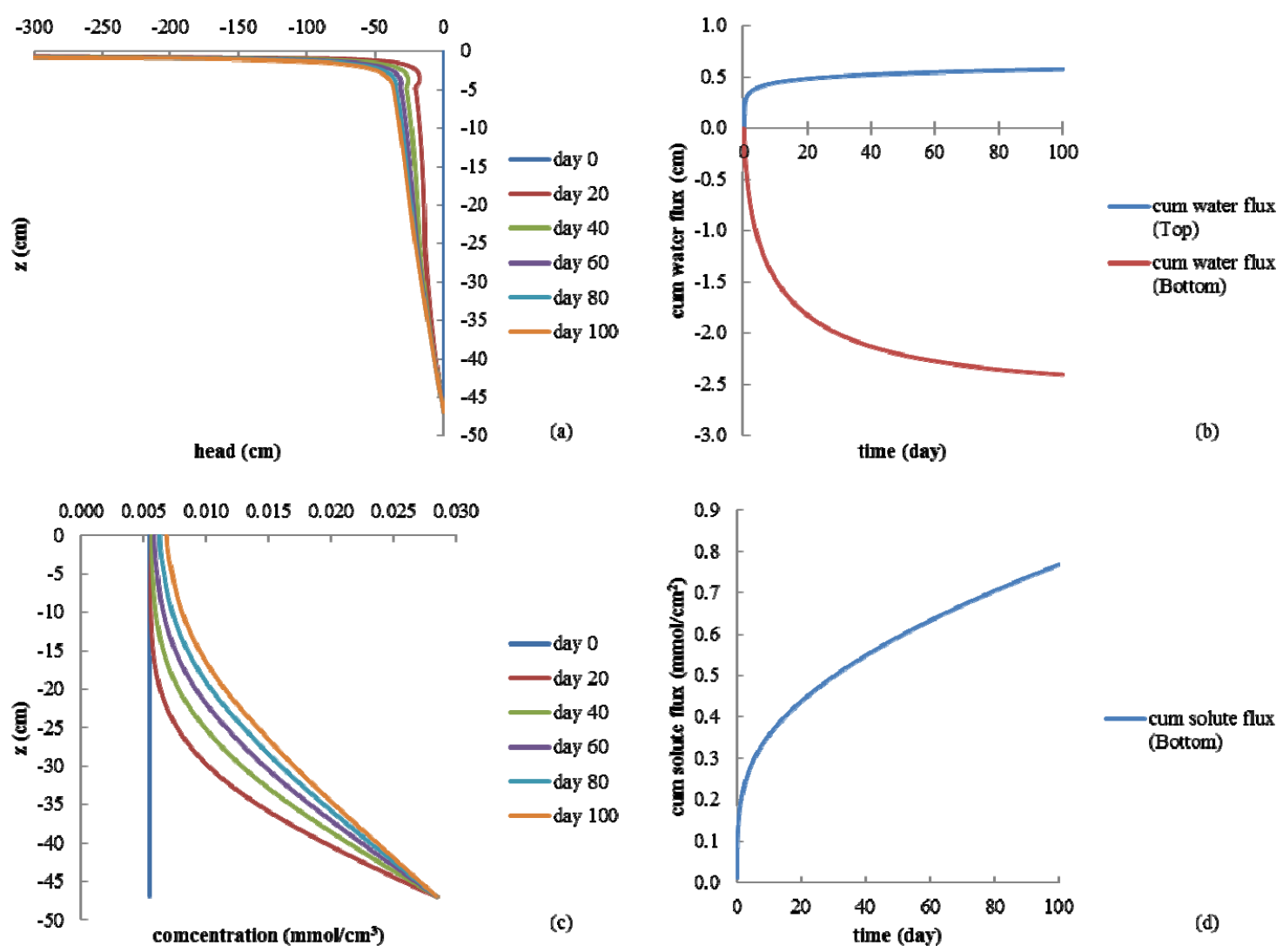

Figure 10. Simulation outputs from Hydrus-1D for dry season accumulation of salt scenario: (a) pressure head profile, (b) cumulative water fluxes, (c) Na concentration profile, and (d) cumulative bottom solute flux

\subsubsection{Mung Bean Cropping during Dry Season}

The result on pressure head profiles of this scenario were shown as averages of the value calculated before and after irrigation throughout the simulation period (figure (11a)). The pressure head profile one day after irrigation suggested downward movement of water according to gravity flow $(\mathrm{dh} / \mathrm{dz}=0$, and $\mathrm{dH} / \mathrm{dz}=1)$. On the other hand, pressure head profile before irrigation suggested movement on both directions. Detailed observation on output data revealed that transition zone occurred at $-20 \mathrm{~cm}$ depth where upward movement appeared in -20 to 0 $\mathrm{cm}$ layer and downward movement commenced in -47 to $-20 \mathrm{~cm}$ layer. Cumulative water flux at the top surface was the irrigation water minus evaporation as shown in figure (11b) along with cumulative root water uptake (transpiration) and cumulative flux at the bottom surface (drainage). In the long run if soil water content in the column was a constant, then the drainage water was the difference between fluxes at the top surface and root water uptake. Na concentration profile given in figure (11c) suggested accumulation by upward movement of saline water from water table by the process of molecular diffusion as in the case of the $3^{\text {rd }}$ scenario. It was noticed that the amount accumulated in this case was higher since the diffusion coefficient was higher in response to higher average water content. Accumulation rate was observed to be faster during the first three irrigation cycles (21 days) and slower during the rest of the simulation period as might be seen in figure (11d). Balance sheet of $\mathrm{Na}$ indicated an influx of $81.80 \mathrm{mmol}$ (table 6) slightly higher than the dry season accumulation of salt scenario, accounting for net accumulation of $127.29 \mathrm{mmol}$ of $\mathrm{Na}$ at the end of simulation period. 

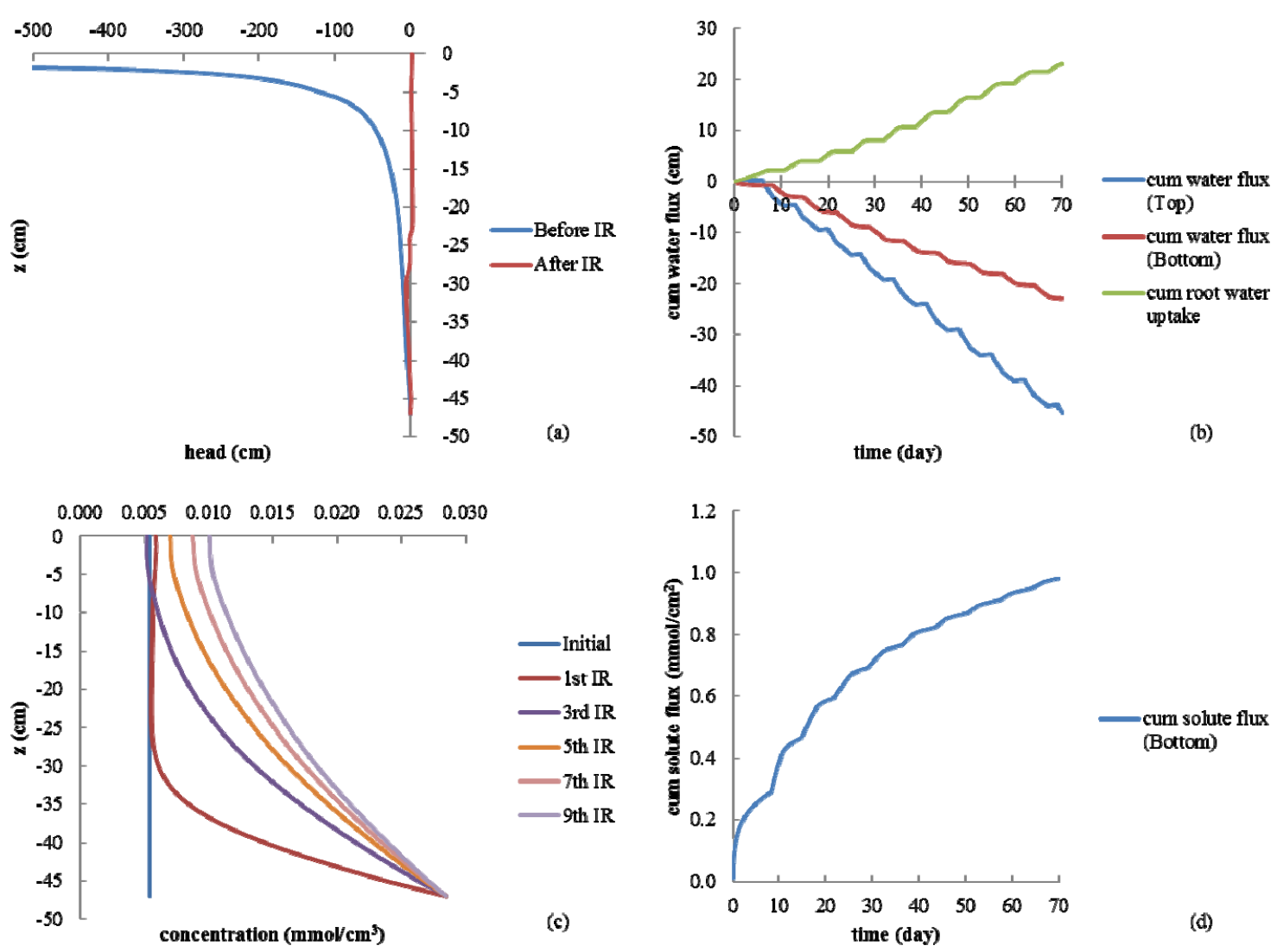

Figure 11. Simulation outputs from Hydrus-1D for Mung bean cropping during dry season scenario: (a) pressure head profile, (b) cumulative water fluxes and plant water uptake, (c) Na concentration profile, and (d) cumulative bottom solute flux

\subsubsection{Reduction of Salt Accumulation by Diminution of Capillary Rise under Mung Bean Cropping}

The purpose of this scenario was to simulate the effect of a layer of large soil crumbs on diminishing capillary rise and thereby the upward movement of salt through the layer. In this experiment a layer of $10 \mathrm{~cm}$ large crumbs of size 2-3 cm having a specific water retention curve and saturated hydraulic conductivity was inserted in the -20 to $-10 \mathrm{~cm}$ depth interval. The simulation result on pressure head profiles was given in figure (12a). As before, the curves were shown as the average before and after irrigation. The pressure head profiles indicated quite clearly that during the drying period of irrigation cycle the upward movement of water was hindered at $-16 \mathrm{~cm}$ datum due to very small value of hydraulic conductivity as the layer dried. Cumulative fluxes presented in figure (12b) revealed that more water was absorbed by mung bean roots than the former scenario and one could see that the cumulative root water uptake was also less wavy. This might result from fast drainage of irrigation water through the surface layer such that water saturated condition, and hence soil aeration and water absorption blockade, occurred in short period of time. And as the result of more crop water uptake, drainage water was seen to be smaller than the former scenario. Concentration profile of $\mathrm{Na}$ presented in figure (12c) revealed that upward movement of $\mathrm{Na}$ ion by diffusion process was restricted as compared to the former scenario where capillary rise blockade layer was not present. Accumulation of salt presented in figure (12d) followed the same trend as before but to the lesser extent as compared to scenarios 3 and 4. Balance sheet of Na ion in table (6) confirmed the phenomenon accounting only $61.32 \mathrm{mmol}$ of $\mathrm{Na}$ influx and $105.41 \mathrm{mmol}$ of total accumulation at the end of 70 days of simulation. 

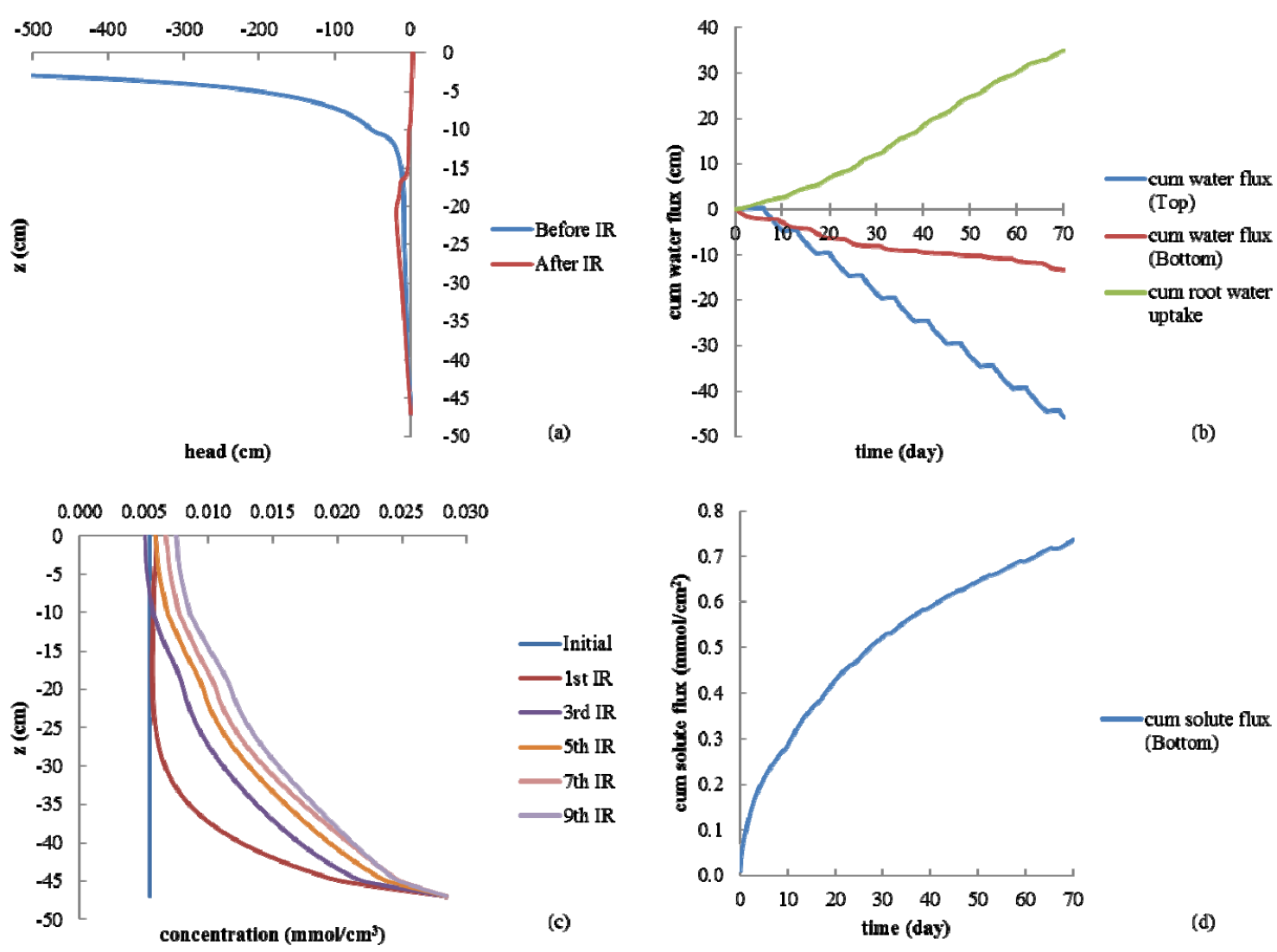

Figure 12. Simulation outputs from Hydrus-1D for reduction of salt accumulation by diminution of capillary rise under mung bean cropping scenario: (a) pressure head profile, (b) cumulative water fluxes and plant water uptake, (c) Na concentration profile, and (d) cumulative bottom solute flux

Table 6. Balance sheet of $\mathrm{Na}$ in $0-47 \mathrm{~cm}$ soil layer at the end of simulation period for all scenarios

\begin{tabular}{crrr}
\hline Scenario & Total Na (mmol) & Total Na influx(+)/efflux(-) $(\mathrm{mmol})$ & Net Na (mmol) \\
\hline 1 & 197.99 & -105.17 & 92.82 \\
2 & 195.39 & -40.68 & 154.71 \\
3 & 45.04 & 63.98 & 109.02 \\
4 & 45.49 & 81.80 & 127.29 \\
5 & 44.09 & 61.32 & 105.41 \\
\hline
\end{tabular}

\section{Conclusion}

Van Genuchten's parameters, namely; $\theta_{\mathrm{s}}, \theta_{\mathrm{r}}, \alpha$, and $\mathrm{n}$ were found to be $0.5218,0.3683,0.0176 \mathrm{~cm}^{-1}$, and 1.3806 , respectively. And the saturated hydraulic conductivity, $\mathrm{K}_{\mathrm{s}}$, was $0.00826 \mathrm{~m} /$ day. The solute transport parameters namely; $\mathrm{k}_{\mathrm{d}}$ and $\eta$ were $1.4418 \mathrm{~cm}^{3} / \mathrm{g}$ and $13.9956 \mathrm{~cm}^{3} / \mathrm{mmol}$, respectively. All of these parameters were determined at $1.267 \mathrm{~g} / \mathrm{cm}^{3}$ bulk density. Mathematical models were constructed to relate the transport parameters to $\rho_{\mathrm{b}}$. Satisfactory result was obtained as the predicted parameters were assigned to Hydrus-1D to simulate the breakthrough curves during salinization and desalinization events of soil column. The simulation results of 5 scenarios by Hydrus-1D yielded conclusive information that during wet season, the best method for salt leaching was continuous flooding. Electrical conductivity of soil solution decreased from initial value of $6 \mathrm{dS} / \mathrm{m}$ at the beginning to $3 \mathrm{dS} / \mathrm{m}$ at the end of the simulation period. Wet and dry rice cropping scenario resulted leaching of salt during the first 42 days where the plant was in the stages of seedling to tillering. The EC of soil solution decreased from initial value of $6 \mathrm{dS} / \mathrm{m}$ to $4.7 \mathrm{dS} / \mathrm{m}$. During the later stages of growth to the end of simulation 
where root water uptake increased and drainage water decreased, further leaching of salt was practically stop. Leaving the soil to evaporate naturally during the dry season where the soil profile was initially saturated and having EC of $2 \mathrm{dS} / \mathrm{m}$ resulted in bi-direction movement of water having a transition zone at $-5 \mathrm{~cm}$ depth. Small amount of evaporation and drainage waters were found throughout 70 days of simulation period. Accumulation of salt in this case was found to occur by the process of diffusion where the main region of deposition was in -47 to $-20 \mathrm{~cm}$ depth and EC of soil solution varied in the range 3 to $6 \mathrm{dS} / \mathrm{m}$. If the soil was cultivated for mung bean production during the dry season where irrigation water was fed at the amount to satisfy crop requirement, continual movement of salt from saline water table was found in response to higher soil moisture. Accumulation of salt in this case was higher than leaving the soil to dry naturally (EC 3.0 as compared to $2.3 \mathrm{dS} / \mathrm{m}$ at soil surface). Insertion of large crumb layer to hinder capillary rise of water was found to limit the upward movement of salt such that its accumulation in the surface layer was comparable to leaving the soil to dry naturally. By this practice, mung bean crop could be produced during the dry season with minimum influence of salt from saline water table.

\section{Acknowledgments}

The authors wish to acknowledge Mr. Sunchai Phungern for his assistance in laboratory works and advance mathematical calculations, and the Department of Soil Science, Kasetsart University at Kampangsean for laboratory facilities.

\section{References}

Dutthuyawat, A. (2011). Coping with risk and vulnerability to salinization in Ho Klong Village Nong Sim Sub-district, Borabue District, Maha Sarakham Province (Unpublished master's thesis). Chiang Mai University, Chiang Mai, Thailand.

Jury, W. A., Gardner, W. R., \& Gardner, W. H. (1991). Soil Physics, 5th edition. New York, USA: John Willey \& Son, Inc.

Yong, L., Šimnuek, J., Longfei, J., Zhentin, Z., \& Lixiao, N. (2014). Evaluation of water movement and water losses in adirect-seeded-rice field experiment using Hydrus-1D. Agricultural Water Management, 142, 38-46. http://dx.doi.org/10.1016/j.agwat.2014.04.021

Yong, L., Šimnuek, J., Longfei, J., Zhentin, Z., \& Lixiao, N. (2015). Evaluation of nitrogen balance in a direct-seeded-rice fieldexperiment using Hydrus-1D. Agricultural Water Management, 148, 213-222. http://dx.doi.org/10.1016/j.agwat.2014.10.010

Rowell, D. L. (1995). Soil Science: Methods and Applications. Essex, England: Addison Wesley Longman Limited.

Šimnuek, J., Šejna, M., Saito, H., Sakai, M., \& Van Genuchten, M. Th. (2013). The HYDRUS-1D Software Package for Simulating the One-Dimensional Movement of Water, Heat, and Multiple Solutes in $\begin{array}{llllll}\text { Variably-Saturated } & \text { Media } & \text { Version } & 4 . & 16 . & \text { Retrieved }\end{array}$ http://www.ars.usda.gov/sp2UserFiles/Place/20360500/pdf_pubs/P2119.pdf

United States Salinity Laboratory Staff. (1954). Diagnosis and Improvements of Saline and Alkali Soils. Washington, DC: United States Department of Agriculture. Agriculture Handbook No. 60.

Van Donk, S. J., Tollner, E. W., Steiner, J. L., \& Evett, S. R. (2004). Soil temperature under a dormant Bermuda grass mulch: Simulation and measurement. Am. Soc. Agric. Eng., 47, 91-98. http://dx.doi.org/10.13031/2013.15874

Verasan, V., Sichantr, K., Karuna, S., Munrat, T., \& Hengcharoen, A. (2006). List of scientific equipment designed and developed by the Department of Soil Science during 2004-2006 (Unpublished technical report). Nakorn Pathom, Thailand: Department of Soil Science, Kasetsart University at Kampangsaen.

\section{Copyrights}

Copyright for this article is retained by the author(s), with first publication rights granted to the journal.

This is an open-access article distributed under the terms and conditions of the Creative Commons Attribution license (http://creativecommons.org/licenses/by/3.0/). 